\title{
Abdominopelvic mass in postmenopausal female: a diagnostic dilemma
}

\author{
Neha Pruthi*, Jyotsna Suri, Saumya Prasad, Anil K. Jain, Pratima Mittal
}

Department of Obstetrics and Gynaecology, Vardhman Mahavir Medical College and Safdarjung Hospital, New Delhi, India

Received: 18 June 2016

Accepted: 09 July 2016

\section{*Correspondence:}

Dr. Neha Pruthi,

E-mail: drnehapruthi@rediffmail.com

Copyright: (c) the author(s), publisher and licensee Medip Academy. This is an open-access article distributed under the terms of the Creative Commons Attribution Non-Commercial License, which permits unrestricted non-commercial use, distribution, and reproduction in any medium, provided the original work is properly cited.

\section{ABSTRACT}

Abdominopelvic masses have varied presentations and pose a diagnostic challenge especially in postmenopausal women where a detailed evaluation is needed to rule out malignancy. Here we report a case of postmenopausal woman with diagnostic discrepancies in clinical findings, radiological investigations and histopathological observation.

Keywords: Postmenopausal, Abdominopelvic mass, Ovarian fibrothecoma

\section{INTRODUCTION}

Abdominopelvic masses in postmenopausal females need a high index of suspicion to determine whether they are benign or malignant. Extra uterine masses, however, pose a greater diagnostic challenge. Differential diagnosis of solid abdominopelvic extra uterine masses include pedunculated/intraligamentous leiomyomas or ovarian masses (ovarian fibroma/fibrothecoma, brenner tumors, granulosa cell tumors, dysgerminoma, krukenberg). Although imaging techniques help in making diagnosis but histopathology plays a key role to rule out other differential diagnosis. ${ }^{1}$ Here we present a case of postmenopausal woman clinically suspected to have a malignant ovarian tumor due to rapid growth of mass and sudden weight loss, which after tumor marker evaluation and imaging was diagnosed as broad ligament fibroid and finally turned out to be an ovarian fibrothecoma histopathologically.

\section{CASE REPORT}

A 52 year-old, P4L4 frail postmenopausal female reported to the gynaecological OPD with complaints of pain lower abdomen for four months and a lump in lower abdomen for two months. Abdominal examination revealed a midline multilobulated firm mass in the hypogastrium and left iliac fossa of size corresponding to 16 weeks uterus. It was non-tender with ill-defined margins and its lower limit could not be reached. On vaginal examination, the same mass $(10 \times 10 \mathrm{~cm})$ was felt anterior to uterus and in left fornix, contiguous with uterus. It was non-tender, mobile but cervical movements were not transmitted to the mass. Based on history and pelvic examination, it was diagnosed as malignant ovarian tumor.

Routine hematological and biochemical investigations were within normal limits. All tumor markers were also in normal range. Pelvic ultrasonography showed a large fibroid measuring $11.3 \times 8.2 \times 8.4 \mathrm{cms}$ in left adenexa, anteverted uterus with endometrial thickness $4 \mathrm{~mm}$. The MRI revealed a well-defined lobulated mass lesion $(12 \times 6.5 \times 9.3 \mathrm{~cm})$ lying anterior to uterus and superior to bladder. It appeared to displace uterus posteriorly, anteriorly it reached up to anterior abdominal wall; superiorly it extended up to level L5-S1, inferiorly it compressed the dome of bladder and posterolaterally lesion it seemed to stretch the broad ligament. It had heterogeneous signal intensity (Figure 1), hyper intense compared to myometrium and iliopsoas on T2 and was isointense to myometrium, hyper intense to iliopsoas on T1. Based on imaging, it was diagnosed as left broad ligament fibroid. 
Exploratory laparotomy revealed a left ovarian mass $15 \times 10 \times 10 \mathrm{~cm}$ in size, multilobulated, greyish white in color. Uterus, bilateral fallopian tube and right ovary appeared normal (Figure 2).

Pan hysterectomy specimen sent for histopathological examination revealed spindle cells with elongated to oval nucleus in intersecting bundles and focal storiform pattern in left ovary. Admixed with this were tumor cells having abundant pale cytoplasm and round to spindle nucleus along with conspicuous hyaline plaques (Figure 3 ). Tumor cells were positive for vimentin and negative for inhibin (Figure 4). Finally, the abdominopelvic mass was diagnosed as fibrothecoma left ovary.

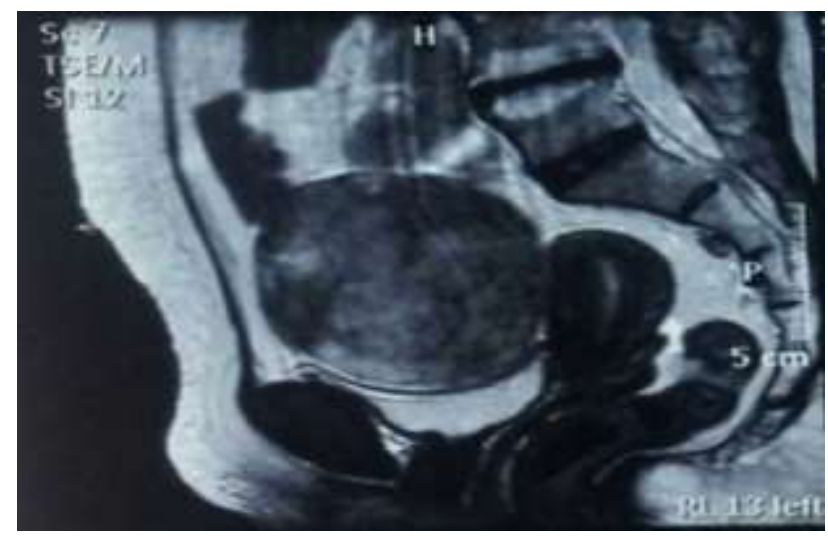

Figure 1: MRI showing heterogeneous signal intensity in the abdominopelvic mass.

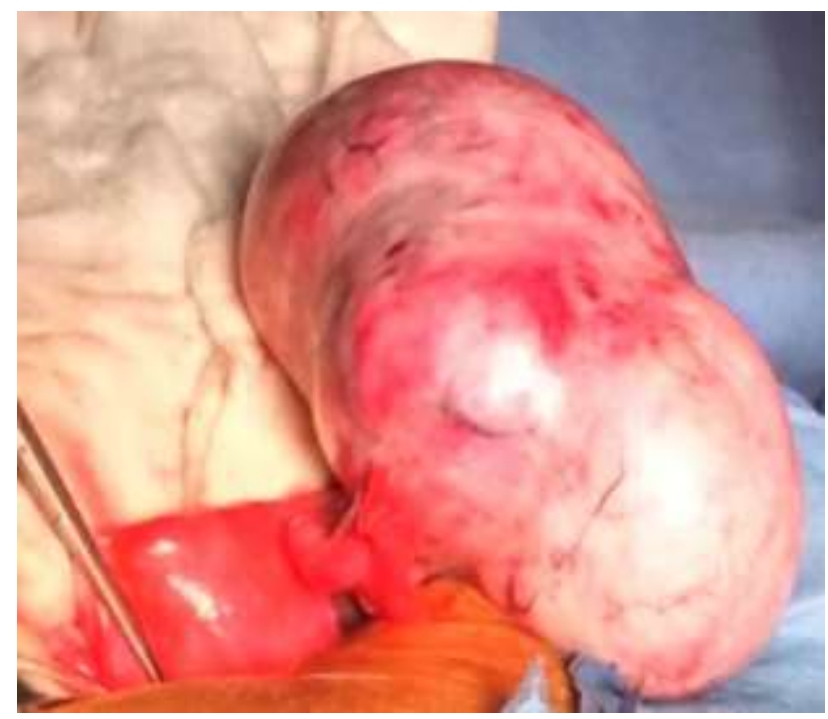

Figure 2: Peroperative finding; left ovarian multilobulated solid mass.

\section{DISCUSSION}

Ovarian fibrothecomas are mesenchymal in origin and are seen most often in postmenopausal females. These tumours of gonadal stromal cell origin account for $1.2 \%$ of all ovarian cancers. ${ }^{1}$

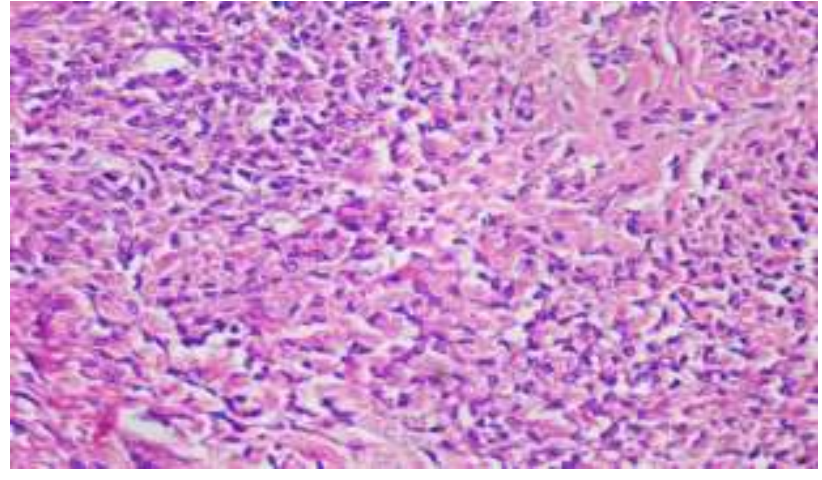

Figure 3: Histopathology of ovarian fibrothecoma.

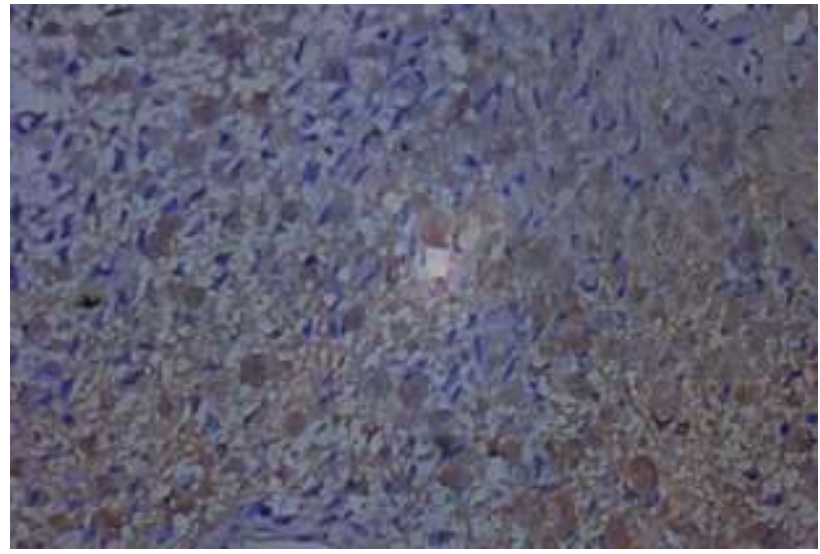

Figure 4: Immunohistochemistry; tumor cells vimentin positive and inhibin negative.

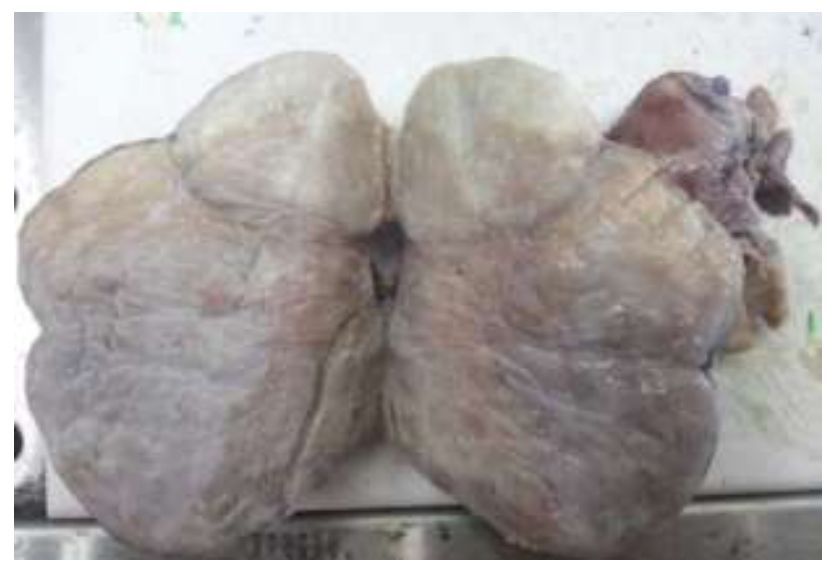

Figure 5: Cut section of ovarian mass.

They are usually benign and unilateral in $90 \%$ cases [2]. Fibrothecomas are commonly seen in older postmenopausal women. ${ }^{2}$ Clinical presentation is often non-specific and patients generally present with a pelvic mass, metrorrhagia and pelvic pain. ${ }^{3}$ Ovarian fibromas may be associated with Meigs syndrome (characterized by the presence of hydrothorax, ascites and elevated CA 125 levels), or basal cell nevus syndrome (bilateral ovarian fibromas, multiple basal cell carcinoma of skin, odontogenic keratocysts, etc.). ${ }^{4}$ Due to their solid structure, these benign tumours are sometimes confused 
with malignant tumours during clinical evaluation as occurred in our case in which the history and examination strongly pointed towards a malignant etiology.

Ultrasound features of ovarian fibrothecomas are nonspecific, however, other imaging techniques like MRI may help in diagnosis. ${ }^{5}$ Fibrothecomas typically show predominantly low signal intensity on $\mathrm{T} 2$-weighted images. ${ }^{6}$ In our case, however, heterogeneous signal intensity was seen which added confusion to our diagnosis. On the basis of imaging modalities broad ligament fibroid was diagnosed and exploratory laparotomy was carried out which revealed an entirely different entity i.e. a solid ovarian mass (Figure 5) which was confirmed histopathologically as benign ovarian fibrothecoma. As in our case, Son et al in his study also concluded that ovarian fibromas are often misdiagnosed as uterine myomas and sometimes mistaken for malignant tumors of ovary preoperatively. ${ }^{7}$ Besides, there have been case reports where broad ligament fibroid imitate ovarian tumor, but in our case it was an ovarian tumor which was mimicking a broad ligament fibroid radiologically. ${ }^{8,9}$

Although fibrothecomas are of low malignant potential but their benign nature cannot be definitely diagnosed preoperatively and therefore, a safe removal must be achieved without peritoneal contamination. ${ }^{10,11}$

\section{CONCLUSION}

Ovarian fibrothecomas though uncommon benign tumors should be considered in differential diagnosis of postmenopausal females with solid abdominopelvic mass, the differential diagnosis being malignant ovarian tumor and fibroid uterus. Imaging techniques should be used as a guide but overall clinical picture together with intraoperative and histopathological examination is essential for making the correct diagnosis.

Funding: No funding sources Conflict of interest: None declared Ethical approval: Not required

\section{REFERENCES}

1. Quirk JT, Natarajan N. Ovarian cancer incidence in the United States, 1992-1999. Gynecol Oncol. 2005;97(2):519-23.

2. Chechia A., Attia L., Temime R.B., Makhlouf T., Koubaa A. Incidence, clinical analysis, and management of ovarian fibromas and fibrothecomas. Am J Obstet Gynecol. 2008;199(473):e1-4.

3. Bazot M, Ghossain MA, Buy JN, Deligne L, Hugol D, Truc JB. Fibrothecomas of the ovary: CT and US findings. J Comput Assist Tomogr. 1993;17:754-9.

4. Angeles RM, Salem FL, Sirota RL. A right ovarian mass in a 71-year-old woman with ascites and elevated CA 125 level. Fibrothecoma of the right ovary. Arch Pathol Lab Med. 2005;129:701-2.

5. Shinagare AB, Meylaerts LJ, Laury AR, Mortele KJ. MRI features of Ovarian Fibroma and Fibrothecoma With Histopathological Correlation. AJR Am J Roentgenol. 2012;198(3):W296-303.

6. Troiano R.N., Lazzarini K.M., Scoutt L.M., Lange R.C., Flynn S.D., McCarthy S. Fibroma and fibrothecoma of the ovary: MR imaging findings. Radiology. 1997;204:795-8.

7. Son CE, Chai JS, Lee JH, Seung WJ, Hong JH, Bae JW. Laparoscopic Surgical Management and Clinical Characteristics of Ovarian Fibromas. Journal of Society of Laparoscopic Surgeons. 2011;15:16-20.

8. Bansal P, Garg D. A Case of Massive Broad Ligament Leiomyoma Imitating an Ovarian Tumor. Journal of Clinical and Diagnostic Research. 2014;8(3):136-7.

9. Godbole RR, Lakshmi KS, Vasant K. Rare case of giant broad ligament fibroid with myxoid degeneration. J Sci Soc. 2012;39(3):144-6.

10. Najmi Z, Mehdizadehkashi A, Kadivar M, Tamannaie Z, Chaichian S. Laparoscopic Approach to a Large Ovarian Fibroma: A Case Report. J Reprod Infertil. 2014;15(1):57-60.

11. Târcoveanu E, Dimofte G, Niculescu D, Vasilescu A, Moldovanu R, Ferariu D. Ovarian Fibroma in the Era of Laparoscopic Surgery: a General Surgeon's Experience. Actachirbelg. 2007;107(6):664-9.

Cite this article as: Pruthi N, Suri N, Prasad S, Jain AK, Mittal P. Abdominopelvic mass in postmenopausal female: a diagnostic dilemma. Int J Reprod Contracept Obstet Gynecol 2016;5:2878-80. 